\title{
1 Operating Costs and Energy Demand of Wastewater Treatment Plants in Austria: Benchmarking Results of the Last 10 Years
}

\author{
J. Haslinger*, S. Lindtner**, J. Krampe* \\ *Institute for Water Quality, Resources and Waste Management, TU Wien, Karlsplatz 13/226-1, 1040 Wien, \\ Austria \\ **k2W Environmental Technology, Development and Consulting, Obere Augartenstraße 18/7/14, 1020 Wien, \\ Austria \\ E-mail address of corresponding author: jhaslinger@iwag.tuwien.ac.at
}

\begin{abstract}
This work presents operating costs and energy consumption of Austrian municipal WWTPS ( $\geq 10,000$ PE-design capacity) classified into different size groups. Different processes as well as cost elements are investigated and processes with high relevance regarding to operating costs and energy consumption are identified. Furthermore, the work shows the cost-relevance of six investigated cost elements. The analysis demonstrates the size-dependency of operating costs and energy consumption. For the examination of the energy consumption the investigated WWTPs were further classified into WWTPs with aerobic sludge stabilisation and WWTPs with mesophilic sludge digestion. The work proves that energy consumption depends mainly on the type of sludge stabilisation. The results of the investigation can help to determine reduction potentials in operating costs and energy consumption of WWTPs and form a basis for more detailed analysis which helps to identify cost and energy saving potentials.
\end{abstract}

Keywords: energy consumption; energy self-sufficiency; operating costs; WWTP benchmarking

\section{Introduction:}

Wastewater treatment plant (WWTP) benchmarking contributes to the identification of optimisation and cost reduction potential (Lindtner et al. 2008). As stated in Foladori et al. (2015), an energy saving potential is almost always present in WWTPs. Baumann \& Roth (2008) and Haberkern et al. (2008) describe target and guide numbers for the evaluation of energy efficiency of WWTPs. A detailed energy analysis can help to identify optimisation potential and to reduce energy consumption at each stage/process/unit of a WWTP, whereat the increase of energy efficiency does not involve necessarily significant investments (Foladori et al. 2015). Performance indicator systems for WWTPs are described in literature (e.g. Balmér \& Hellström 2012, Quadros et al. 2010). In Austria a benchmarking method was developed from 1999 to 2004; the aim is the identification of best performing WWTPs and the determination of cost reduction potentials to improve the cost efficiency (Kroiss \& Lindtner 2005). Within the last 10 years almost every second Austrian municipal WWTP treating more than 10,000 population equivalents (PE, expressed as PE-design capacity) participated at least once in the annual benchmarking. With regard to PE, about $56 \%$ of the Austrian municipal WWTP capacity is included in the benchmarking data pool. The representativity of the data for all Austrian WWTPs was investigated and confirmed (Lindtner \& Vohryzka 2015). This work investigates operating costs and energy consumption data from 104 Austrian municipal WWTPs ( $\geq 10,000$ PE) which participated at least once in the annual benchmarking in the years 2003 to 2013, whereof 16 WWTPs are treating more than 100,000 PE. All costs are indexed to the year 2013 and in cases where a WWTP participated more than once, mean values are calculated. This work shows the results of the analysis and interpretation of the benchmarking pool data and provides an insight into operating costs and energy consumption of Austrian municipal WWTPs. All investigated WWTPs fulfil the legal requirements regarding wastewater treatment (95\% biochemical oxygen demand-, 85\% chemical oxygen demand- and $70 \%$ total nitrogen-removal; total phosphorus threshold 0.5 or $1.0 \mathrm{mg} / \mathrm{L}$ depending on plant size and receiving water).

CIWA Publishing [2016]. The definitive peer-reviewed and edited version of this article is published in Water Science \& Technology, Volume 74, Issue 2, 2620-2626, 2016, https://doi.org/10.2166/wst.2016.390 and is available at www.iwapublishing.com.

This is the accepted version. 


\section{Methods:}

The Austrian Benchmarking Method is described in detail in Lindtner et al. (2004). To enable the comparison of WWTPs of different process and operation modes, operating costs of wastewater treatment plants are split into the following main and support processes: mechanical pretreatment (process 1; P1), mechanical-biological wastewater treatment (process 2; P2), sludge thickening and stabilisation (process 3; P3), further sludge treatment and disposal (process 4; P4), obligatory processes (support process I; SPI) and optional processes (support process II; SPII).

For each process yearly specific operating costs and specific energy consumptions are calculated based on annual data provided by the plants, whereat the operating costs are split into six cost elements (i.e. personnel costs, energy costs, residue treatment costs, material costs, external costs and other costs). Specific costs and specific energy consumptions are based on organic pollution load expressed in PE-COD120 (120 g chemical oxygen demand/PE/d corresponding to $60 \mathrm{~g}$ biochemical oxygen demand during 5 days/PE/d).

\section{Results and Discussion:}

\section{Operating costs:}

Figure 1 illustrates the specific total operating costs of the investigated WWTPs and shows that specific operating costs decrease with increasing design capacity (economy of scale). The yearly specific operating costs of the investigated large plants $(\geq 100,000 \mathrm{PE})$ are 14.6 €/PE-COD120/y (median) and thus considerably smaller than of WWTPs $<100,000$ PE.

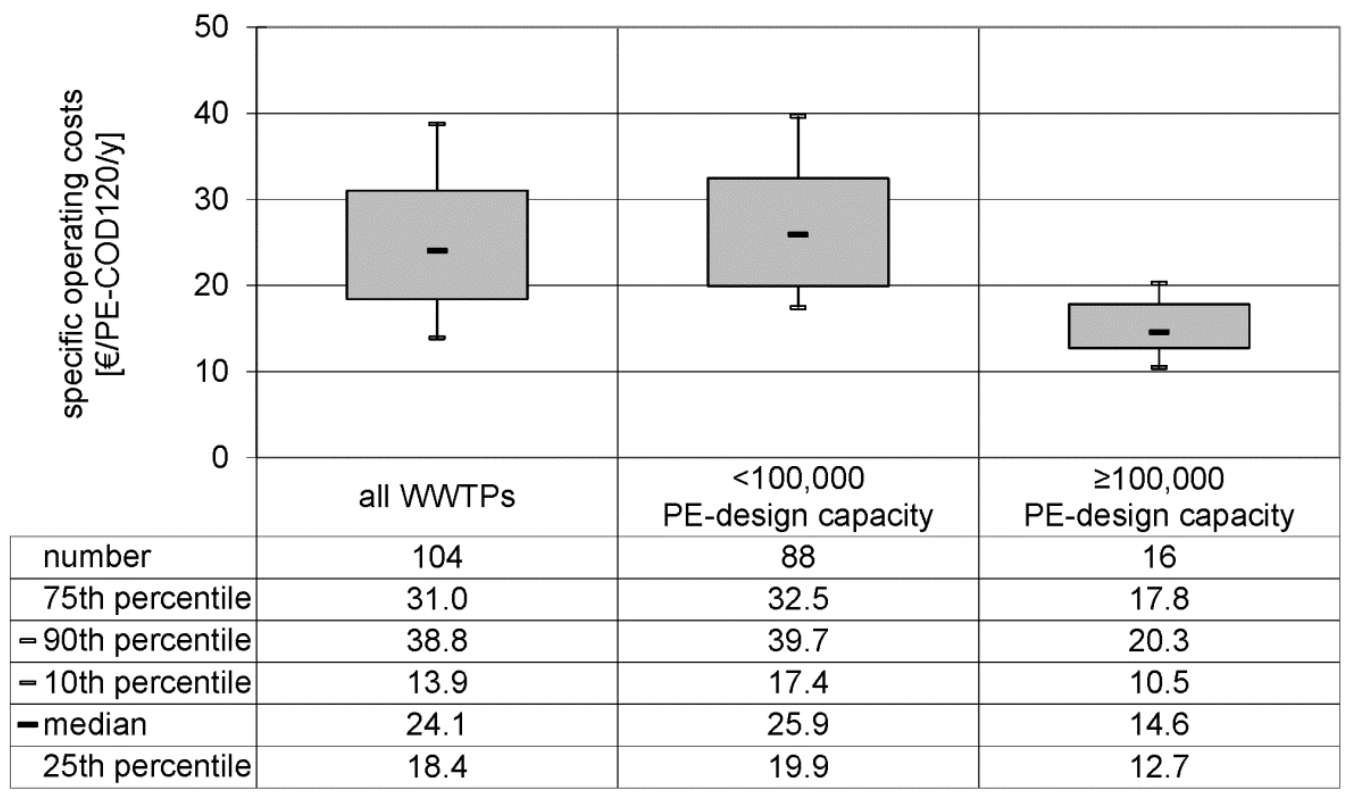

Figure 1: Specific operating costs of municipal WWTPs in Austria 
The detailed analysis of the operating costs is shown in figure 2 and figure 3 . Figure 2 shows that personnel costs are the most relevant cost element at the investigated WWTPs. Energy costs contribute with 17 respectively 11\% to the total operating costs of WWTPs and hence are from lower importance regarding operating costs. Figure 3 shows that support process I (obligatory processes; i.e. laboratory and monitoring, administration, operation building and infrastructure) and process 4 (further sludge treatment and disposal; i.e. dewatering, reuse/disposal) are the most cost-relevant processes on small as well as on large WWTPs. Process 2 (mechanical-biological wastewater treatment; i.e. aeration, biogas utilisation, phosphorus precipitation), the most important process with regard to water pollution control, distributes with only 22 respectively $18 \%$ to the total operating costs.
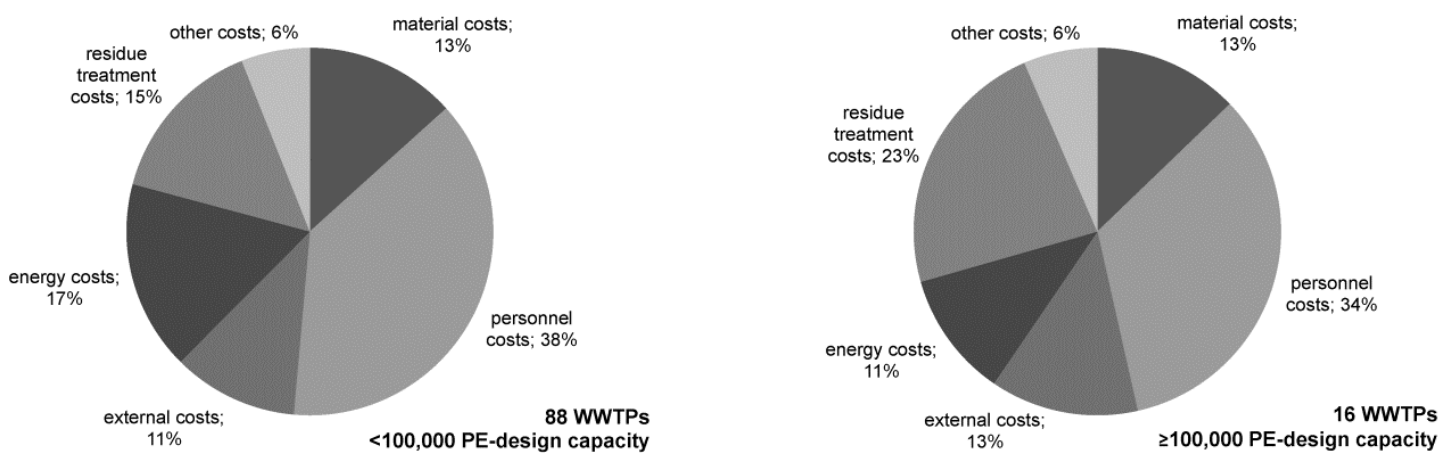

Figure 2: Distribution of cost elements of total operating costs of small and large municipal WWTPs in Austria
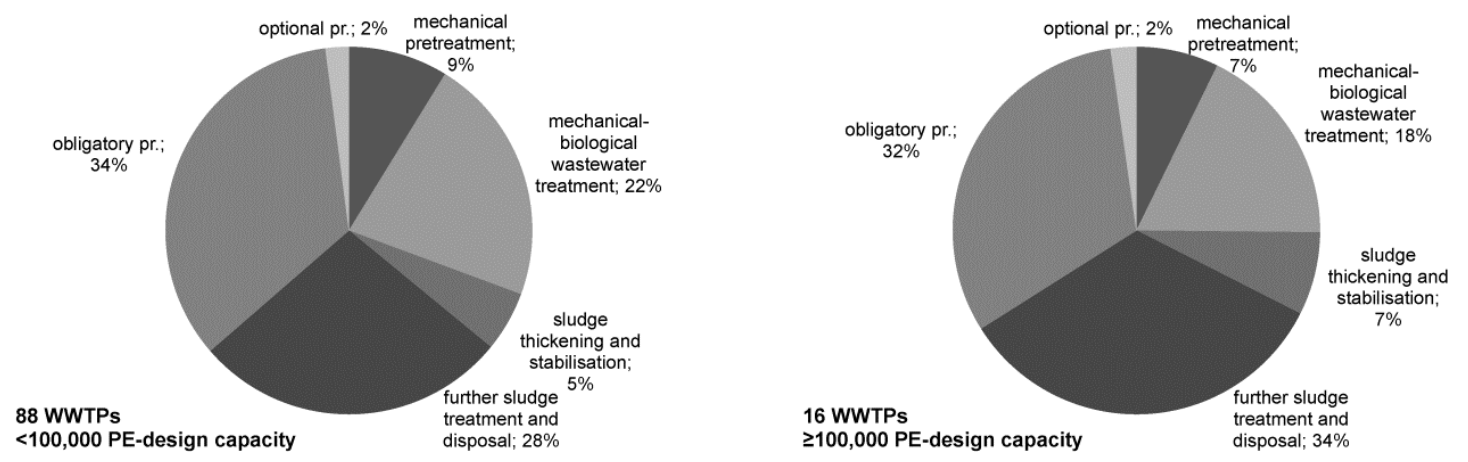

Figure 3: Distribution of processes of total operating costs of small and large municipal WWTPs in Austria

\section{Energy consumption:}

For the following investigations the data of 2 WWTPs were excluded because of implausibility (specific total energy consumption $\leq 15 \mathrm{kWh} / \mathrm{PE}-\mathrm{COD} 120 / \mathrm{y}$ ).

Figure 4 illustrates the specific energy consumption of the investigated WWTPs classified into four groups depending on their plant size. The median of the specific energy consumption of all WWTPs amounts to $36.5 \mathrm{kWh} / \mathrm{PE}-\mathrm{COD} 120 / \mathrm{y}$. Although, variability between the different WWTP sizes is high. The figure demonstrates the size dependency of the energy consumption on WWTPS. One reason is the fact, that small WWTPs, especially WWTPs treating less than 20,000 PE, stabilise their sludge aerobically and therefore consume more energy. 


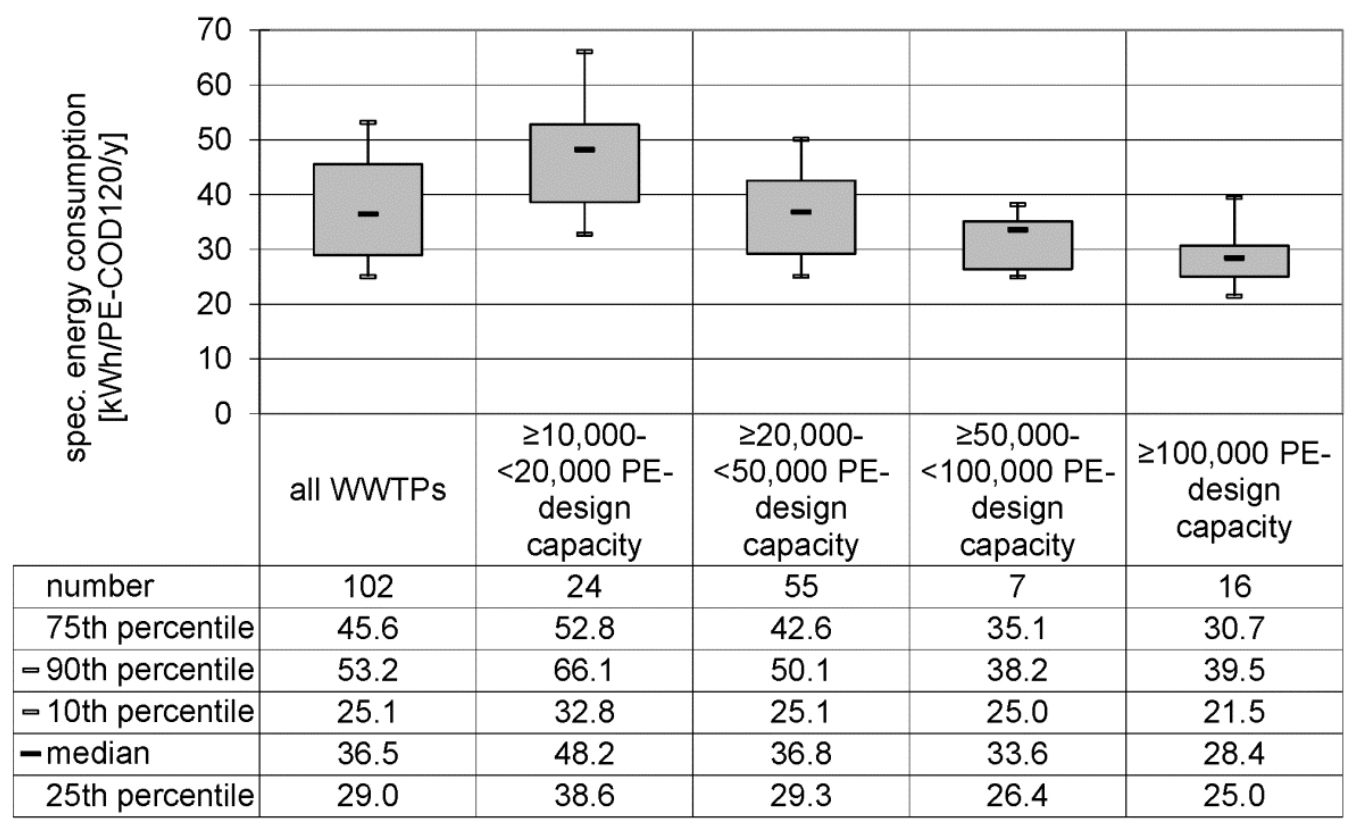

Figure 4: Specific energy consumption of municipal WWTPs in Austria (data without outliers)

Table 1 shows the specific energy consumption of the investigated WWTPs classified into their type of sludge stabilisation. Each category is further subdivided into the plant size. The table shows that WWTPs with aerobic sludge stabilisation have a higher specific energy consumption (about $6 \mathrm{kWh} / \mathrm{PE}-\mathrm{COD} 120 / \mathrm{y}$ ) than WWTPs with mesophilic sludge digestion. This table confirms the dependence of energy consumption on plant size and technology, as also described in literature (Krampe 2013, Mizuta \& Shimada 2010).

Table 1: Specific energy consumption of municipal WWTPs in Austria subdivided into WWTPs with aerobic sludge stabilisation and mesophilic sludge digestion respectively (data without outliers)

\begin{tabular}{|c|c|c|c|c|c|}
\hline \multirow{3}{*}{$\begin{array}{l}\text { spec. energy } \\
\text { consumption } \\
\text { [kWh/PE-COD 120/y] }\end{array}$} & \multirow{3}{*}{$\begin{array}{c}\text { all } \\
\text { WWTPs }\end{array}$} & \multicolumn{4}{|c|}{ WWTPs } \\
\hline & & \multicolumn{2}{|c|}{$\begin{array}{l}\text { with aerobic } \\
\text { stabilisation }\end{array}$} & \multicolumn{2}{|c|}{$\begin{array}{l}\text { with mesophilic } \\
\text { sludge digestion }\end{array}$} \\
\hline & & $\leq 50.000 \mathrm{PE}$ & $>50.000 \mathrm{PE}$ & $\leq 50.000 \mathrm{PE}$ & $>50.000 \mathrm{PE}$ \\
\hline number & 102 & 38 & 1 & 41 & 22 \\
\hline 25th percentile & 29.0 & 33.6 & 34.8 & 29.2 & 25.2 \\
\hline median & 36.5 & 42.2 & 34.8 & 36.8 & 28.4 \\
\hline 75th percentile & 45.6 & 49.9 & 34.8 & 42.5 & 34.2 \\
\hline
\end{tabular}

Figure 5 illustrates the specific energy consumption of the investigated WWTPs. In this figure the WWTPs are subdivided into their type of sludge stabilisation technology. The median of the specific energy consumption of WWTPs with mesophilic sludge digestion amounts to $33 \mathrm{kWh} / \mathrm{PE}-\mathrm{COD} 120 / \mathrm{y}$ and is about $10 \mathrm{kWh} / \mathrm{PE}-\mathrm{COD} 120 / \mathrm{y}$ lower than of WWTPs with aerobic sludge stabilisation. 


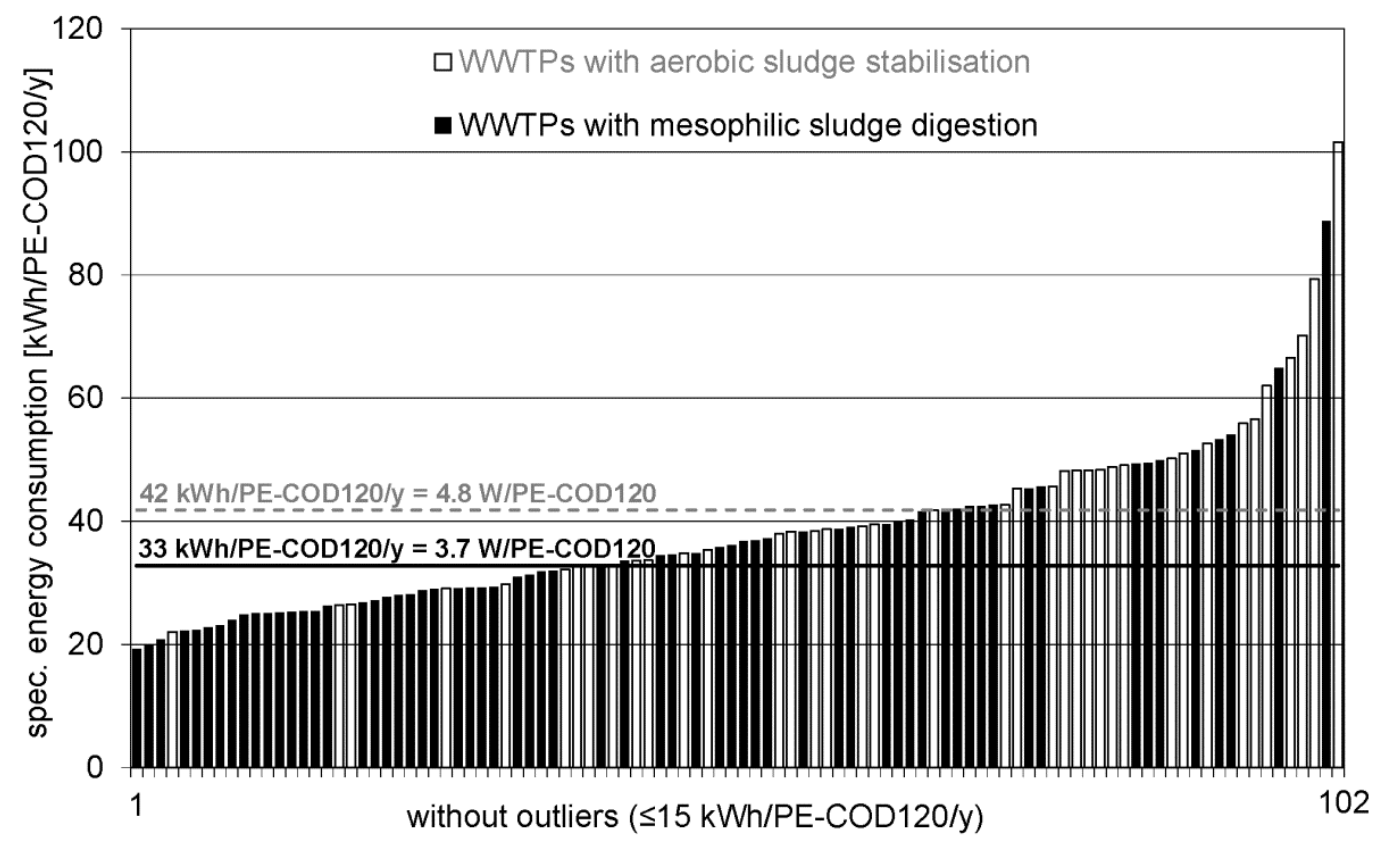

Figure 5: Specific energy consumption and energy demand of municipal WWTPs in Austria (data without outliers)

From the analysis above it can be said that the variation in energy consumption depends mainly on the type of sludge stabilisation, which obviously depends on the size of a treatment plant.

Figure 6 illustrates the energy consumption related to the main and support processes. The figure shows that process 2 (mechanical-biological wastewater treatment) is by far the most relevant process not just with regard to water pollution control, but also with regard to energy consumption. All other main processes (process 1, 3 and 4) are from lower importance regarding energy consumption. The specific energy consumption for sludge thickening and stabilisation contributes with just 8 respectively $12 \%$ to the total energy consumption, because energy consumption for aerobic sludge stabilisation is allocated to process 2 . The support processes (obligatory and optional processes) can be neglected with regard to energy consumption. 

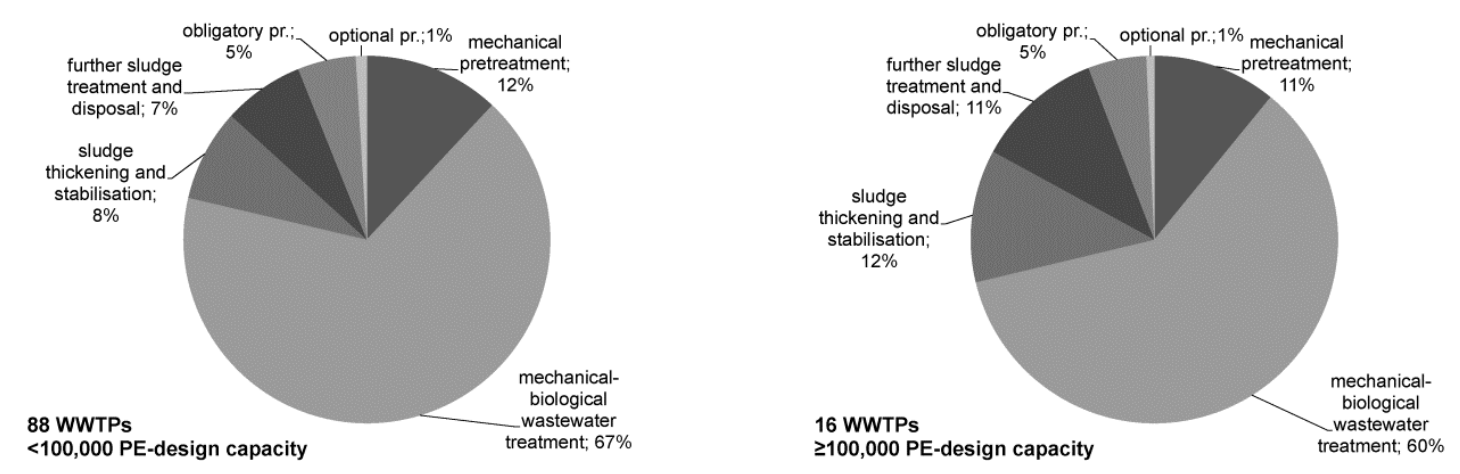

Figure 6: Distribution of processes of total energy consumption of small and large municipal WWTPs in Austria (data without outliers)

Due to the importance regarding energy consumption of process 2, a more detailed analysis was carried out. Figure 7 shows the specific energy consumption of process 2 . The WWTPs are classified into different size groups. The figure shows the size-dependency of the process.

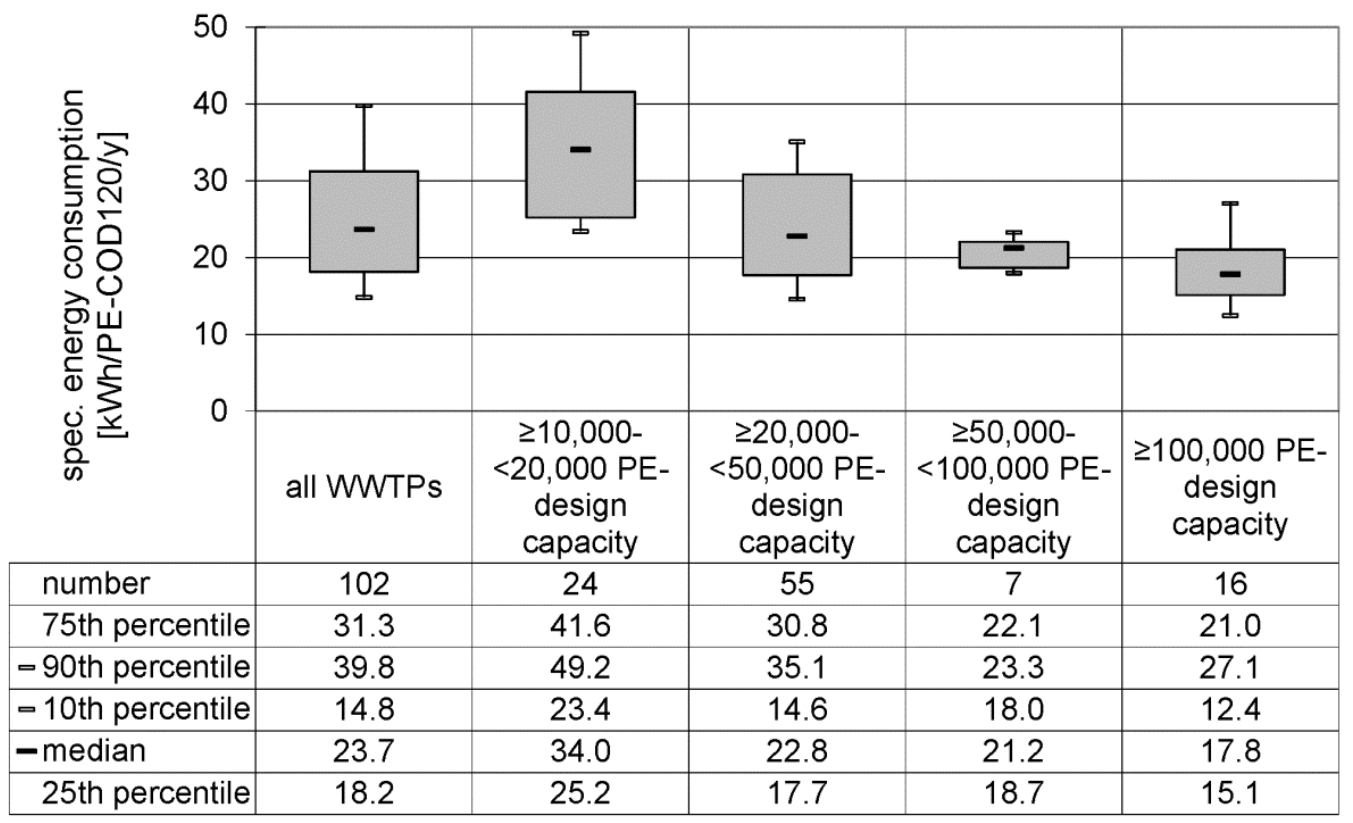

Figure 7: Specific energy consumption of process 2 of municipal WWTPs in Austria (data without outliers)

\section{Energy efficiency:}

Energy-efficiency of WWTPs is from increasing interest, not only due to economic but also due to environmental aspects. Hence, the optimisation of energy consumption and 
Austria are described in Nowak et al. (2011). The examination of the benchmarking data pool shows that 3 of the investigated large and 4 of the small WWTPs operate energy selfsufficient on a yearly basis.

\section{Conclusions:}

Based on a dataset of 104 WWTPs, this work analyses operating costs and energy consumption of municipal WWTPS in Austria. From the presented results, the following main conclusions can be drawn:

- Personnel costs are the most important cost element, distributing with more than $30 \%$ to the total operating costs.

- Energy costs distribute with only 17 respectively $11 \%$ to the total operating costs. However, with regard to environment protection, the reduction of energy consumption at WWTPS is crucial among the increase of energy production. But, as stated in Svardal \& Kroiss (2011), energy minimisation must never negatively affect treatment efficiency due to the importance of water quality conservation.

- Process 4 (further sludge treatment and disposal) shows the highest cost-relevance of all main processes, distributing with about 30\% to the total operating costs.

- The investigated large WWTPs show a yearly specific energy consumption of about $30 \mathrm{kWh} / \mathrm{PE}-\mathrm{COD} 120$. In comparison, the specific energy consumption of smaller WWTPs is about $10 \mathrm{kWh} / \mathrm{PE}-\mathrm{COD} 120 / \mathrm{y}$ higher.

- Process 2 (mechanical-biological wastewater treatment) is by far the most important process regarding energy consumption (67 respectively $60 \%$ of total energy consumption). For the identification of further optimisation potential splitting of the process (e.g. aeration, mixing,...) would be necessary. Confirming Foladori et al. (2015) who stress the importance to collect relevant data for process optimisation.

- Operating costs and energy consumption decrease with increasing plant size (economy of scale). As the difference in energy consumption is mainly caused by the type of sludge stabilisation, smaller WWTPs with aerobic sludge stabilisation have a much higher specific energy consumption than large WWTPs with mesophilic sludge digestion.

- WWTPs can be operated self-sufficient on a yearly basis. Prerequisites for this are a small specific energy consumption and a high specific energy production (including digestion of co-substrate).

As for international comparisons a non-monetary evaluation is necessary, the cost relevance of the above-mentioned processes and cost elements was analysed. Furthermore the relevance of the above mentioned processes regarding energy consumption was illustrated. These results may serve as a basis for international comparisons regarding energy consumption of municipal WWTPs of different size groups and hence may help to identify inefficiencies at WWTPS.

\section{References:}

Balmér, P. \& Hellström, D. 2012 Performance indicators for wastewater treatment plants. Water Science and Technology, 65(7), 1304-1310.

Baumann, P. \& Roth, M. 2008 Senkung des Stromverbrauchs auf Kläranlagen, Leitfaden für das Betriebspersonal (Reduction of the energy consumption of WWTPS, Manual for operators). Heft 4, DWA Landesverband Baden-Württemberg, Stuttgart, Germany.

Foladori, P., Vaccari, M. \& Vitali, F. 2015 Energy audit in small wastewater treatment plants: methodology, energy consumption indicators, and lessons learned. Water Science and Technology, 72(6), 1007-1015. 
Haberkern, B., Maier, W. \& Schneider, U. 2008 Steigerung der Energieeffizienz auf kommunalen Kläranlagen (Increasing the energy efficiency of WWTPs). Umweltbundesamt, Dessau-Roßlau, Germany.

Krampe, J. 2013 Energy benchmarking of South Australian WWTPs. Water Science and Technology, 67(9), 2059-2066.

Kroiss, H. \& Lindtner, S. 2005 Costs and Cost-Effectiveness Analysis for Waste Water Services. Proceedings of IWA Conference on Nutrient Management in Wastewater Treatment, Krakow, Poland, 18.-21. September 2005.

Lindtner, S., Kroiss, H. \& Nowak, O. 2004 Benchmarking of municipal waste water treatment plants (an Austrian project). Water Science and Technology, 50(7), 265-271.

Lindtner, S., Schaar, H. \& Kroiss, H. 2008 Benchmarking of large municipal wastewater treatment plants treating over 100,000 PE in Austria. Water Science and Technology, 57(10), 1487-1493.

Lindtner, S. \& Vohryzka, F. 2015 Der Energieverbrauch österreichischer Kläranlagen (Energy consumption of Austrian wastewater treatment plants). Wiener Mitteilungen 232, Vienna, Austria.

Mizuta, K. \& Shimada, M. 2010 Benchmarking energy consumption in municipal wastewater treatment plants in Japan. Water Science and Technology, 62(10), 2256-2262.

Nowak, O., Keil, S. \& Fimml, C. 2011 Examples of energy self-sufficient municipal nutrient removal plants. Water Science and Technology, 64(1), 1-6.

Quadros, S., Rosa, M. J., Alegre, H. \& Silva, C. 2010 A performance indicators system for urban wastewater treatment plants. Water Science and Technology, 62(10), 2398-2407.

Svardal, K. \& Kroiss, H. 2011 Energy requirements for waste water treatment. Water Science and Technology, 64(6), 1355-1361. 